\title{
PERANCANGAN BUKU FOTOGRAFI DOKUMENTASI KEGIATAN KESENIAN DI KAMPUNG JELEKONG
}

\author{
Sherilyn Silviani, Sandy Rismantojo, R.A. Dita Saraswati \\ (Email: sherilynsilviani@gmail.com) \\ Desain Komunikasi Visual \\ Fakultas Seni Rupa dan Desain \\ Universitas Kristen Maranatha \\ Jl. Surya Sumantri No. 65, Bandung, Indonesia
}

\begin{abstract}
ABSTRAK
Kampung Jelekong merupakan sebuah perkampungan yang terletak di selatan Kota Bandung dan merupakan pusat pengrajin lukisan pesanan. Kegiatan kerajinan lukis tersebut dimulai oleh almarhum Pak Odin Rohidin di tahun 1970an. Selain bergerak di bidang lukisan, Kampung Jelekong juga aktif dalam kesenian pencak silat, wayang golek, dan tari jaipong. Sayangnya, kampung ini sulit mengalami perkembangan dalam hal fasilitas dan infrastruktur karena kurangnya kepedulian pemerintah setempat dan sedikitnya masyarakat Bandung yang mengetahui dan menghargai keberadaan para pengrajin seni di Kampung Jelekong yang memiliki peran penting dalam melestarikan kesenian dan kebudayaan tradisional Sunda. Maka dari itu, perlu dirancang sebuah media yang dapat mendokumentasikan dan menceritakan kegiatan kesenian para pengrajin seni di Kampung Jelekong dan kesulitan yang mereka alami dalam berkarya tanpa dikenal dan dihargai oleh orang-orang sekitarnya. Dengan dirancangnya media buku fotografi dokumentasi, diharapkan masyarakat Bandung bisa mengenal lebih luas tentang para pengrajin seni tersebut dan mendukung adanya pengembangan fasilitas dan infrastuktur untuk meningkatkan kinerja dan semangat mereka dalam berkarya. Perancangan buku ini menggunakan gaya fotografi dokumenter dan fotografi human-interest yang bersifat objektif dan humanis sehingga target audience atau pengamat dapat menghargai keberagaman kesenian yang ada di Kampung Jelekong dan memahami kisah hidup mereka. Fotografi juga dipilih dengan tone yang hangat agar dapat menggambarkan suasana kekeluargaan yang terasa antar penduduk. Penataan layout buku menggunakan pendekatan visual clean design yang menggabungkan fotografi dengan Tipografi Huruf yang memiliki tingkat keterbacaan yang baik. Salah satu bagian dari judul buku juga ditulis menggunakan gaya goresan kuas dan cat akrilik secara manual yang kemudian diproses secara digital agar menggambarkan sifat kebebasan dan kreativitas seni. Buku fotografi ini diharapkan mampu menyampaikan pesannya kepada masyarakat Bandung dan berdampak pada Kampung Jelekong sehingga semakin dikenal dan berkembang.
\end{abstract}

Kata Kunci: buku; dokumenter; fotografi; Jelekong; kesenian

\begin{abstract}
Jelekong Village is located in the south of Bandung and is a craft center for make-by-order painting artisans. The late Mr. Odin Rohidin started this artistic activity in the 1970s. Aside from paintings, Jelekong Village is also active in such activities as Pencak Silat, Wayang Golek, and the Jaipong dance. Unfortunately, this village has a hard time developing in terms of facilities and infrastructures, which is caused by lack of attention from the local government. This results in the fact that not many people, even those in Bandung know the whereabouts of the artisans in Jelekong Village, who in fact play an important role in preserving the traditional Sundanese arts and culture. That is why, there is a need to design a media that is able to document and narrate the things that these artisans do in Jelekong Village and their daily struggles in creating art without being acknowledged and appreciated by their own people. By designing a documentary photography book, it is expected that the people of Bandung will be more informed about these artisans and will support the making of better facilities and infrastructures to rise up their spirit in creating more arts.
\end{abstract}


Serat Rupa Journal of Design, January 2019, Vol.3, No.1: 25-33

E-ISSN: 2477-586X, ISSN: 2338-3348 | https://doi.org/10.28932/srjd.v3i1.811 | Received: 20-05-2018, Accepted: 25-01-2019

Sherilyn Silviani, Sandy Rismantojo, R.A. Dita Saraswati

Perancagan Buku Fotografi Dokumentasi Kegiatan Kesenian Di Kampung Jelekong

In this project, This book using documentary photograpy and human-interest photography styles that are objective with a humanist approach so that the target audience can appreciate the variety of artistry in Jelekong Village and also understand their life stories. This photography style is also being served with a warm tone to visualize the intimacy among the people of Jelekong Village. The layout of the book uses a clean design visual approach paired with photography and some typefaces with a high readibility. One of the parts of the book title is also written manually using a paintbrush style to create the freedom and artistic creativity as the book identity. The writer hopes that this photography book can deliver its message to the people of Bandung and make Jelekong Village prosperous.

Keywords: arts; book; documentary; Jelekong; photography

\section{PENDAHULUAN}

Bandung adalah sebuah kota yang dihuni oleh banyak seniman dengan menghasilkan karya-karya hebat. Selain seniman ada pula artisan atau pengrajin seni yang membuat lukisan dan menjualnya di sepanjang jalan Braga. Mereka membuat lukisan dengan aliran gaya yang diperkirakan laku dijual untuk orang awam untuk dipajang sebagai dekorasi rumah, butik, dan restoran. Karya-karya tersebut juga laku terjual sampai ke Bali, Medan, dan bahkan ke luar negeri, tapi sayangnya masih banyak masyarakat Bandung yang tidak tahu bahwa pengrajin seni yang memproduksi lukisan-lukisan tersebut berasal dari sebuah kampung di pinggiran kota Bandung yaitu Kampung Jelekong. 95 dari 110 responden belum mengetahui mengenai kegiatan kesenian di Kampung Jelekong. 74 responden berpendapat bahwa mereka tertarik terhadap kesenian lukis di Bandung, bahkan 15 responden mengaku sangat tertarik. Kampung Jelekong terletak di Kecamatan Baleendah, Kabupaten Bandung, sekitar 25 kilometer dari pusat kota. Keberadaan Kampung Jelekong sebagai kampung seni diawali oleh Bapak Odin Rohidin (almarhum), yang menyebarkan ilmu lukisnya sepulang dari perantauan pada tahun 1977. Lama-kelamaan, industri kesenian di kampung ini berkembang pesat seiring banyaknya pesanan yang datang dari dalam maupun luar kota. Bapak Iman Budiman selaku seorang pemilik sanggar di Kampung Jelekong mengungkapkan bahwa tenaga pekerja kesenian di Kampung Jelekong sudah sangat siap jika kampung ini padat pengunjung, namun dibutuhkan dukungan pemerintah setempat terhadap infrastruktur dan fasilitas yang dapat mewadahi mereka untuk terus berkarya dan melestarikan kebudayaan Sunda.

Beragam kegiatan kesenian dan kehidupan masyarakat di Kampung Jelekong yang ada di Kampung Jelekong menjadi sebuah objek yang menarik untuk didokumentasikan melalui media buku fotografi. Tujuan dari perancagan karya ini adalah agar masyarakat dapat mengapresiasi karya dan kerja keras para pengrajin dan potensi yang mereka miliki. 


\section{METODE PENELITIAN}

Perancangan ini didukung oleh penelitian pendahuluan yang dilakukan dengan metode kuantitatif dan kualitatif. Secara kuantitatif, dilakukan dengan menyebarkan kuesioner online kepada 110 responden yang berdomisili di daerah Jawa Barat untuk mengetahui seberapa dalam pengetahuan mereka tentang keberadaan Kampung Jelekong dan aktivitas kesenian mereka. Secara kualitatif, dilakukan wawancara kepada narasumber yaitu seorang pengrajin lukis di Kampung Jelekong, yaitu Bapak Iman Budiman, untuk mendapatkan informasi lebih dalam seputar kehidupannya dan pengalamannya sebagai pengrajin lukis di Kampung Jelekong.

Landasan Teori yang dipakai dalam merancang buku ini adalah sebagai berikut:

\section{a. Fotografi Dokumenter}

Dalam bukunya yang berjudul "Photography: a Cultural History" (2002), Mary Warner memberikan definisi dokumenter secara umum, yaitu segala sesuatu yang merepresentasikan hal-hal non-fiksi pada buku atau media visual. Menurut Graham Clarke (1997), fotografi dokumenter merupakan bukti bagi sesuatu hal yang pernah ada atau terjadi, sehingga makna historisnya dapat digunakan pada waktu mendatang sebagai catatan atau laporan kebenaran objektif akan sesuatu hal yang pernah ada atau yang telah terjadi. Fotografi dokumenter memiliki tiga fungsi utama, yaitu sebagai dokumen sejarah yang menceritakan kejadian sesuai faktanya dan mengemasnya dengan estetika yang menarik perhatian audience, dan untuk mendorong adanya perubahan politik dan sosial (Fotografi.upi.edu, 2018).

\section{b. Fotografi Human Interest}

Fotografi human-interest yang memotret kehidupan, gerak-gerik, aktivitas sekumpulan manusia sehingga dapat menimbulkan atmosfer, bahkan rasa simpati tersendiri dari orangorang yang melihatnya (Way, 2014). Dengan gaya ini, buku ini dapat menceritakan kehidupan dan kegiatan pengrajin seni di Kampung Jelekong dari perspektif yang humanis.

\section{c. Modular Grid}

Menurut buku karya Timothy Samara yang berjudul Making and Breaking the Grid (2002), modular grid tepat dipakai untuk layout yang memerlukan stabilitas dan kontrol dalam 
Serat Rupa Journal of Design, January 2019, Vol.3, No.1: 25-33

E-ISSN: 2477-586X, ISSN: 2338-3348 | https://doi.org/10.28932/srjd.v3i1.811 | Received: 20-05-2018, Accepted: 25-01-2019

Sherilyn Silviani, Sandy Rismantojo, R.A. Dita Saraswati

Perancagan Buku Fotografi Dokumentasi Kegiatan Kesenian Di Kampung Jelekong

penataannya. Gaya layout modular dan multicolumn grids sesuai untuk diaplikasikan pada coffee table book mengenai pengrajin seni di Kampung Jelekong karena susunan grid tulisannya yang rapi dan tidak mengalihkan fokus pembaca dari foto-foto yang ditampilkan.

\section{d. Alur Cerita}

Pada sebuah buku dokumentasi juga membutuhkan alur yang merupakan rangkaian struktur kejadian dalam sebuah cerita dari awal sampai akhir, saling berkaitan dan menggambarkan tokoh serta perannya dalam cerita di buku tersebut, semuanya itu terkait dalam kesatuan waktu.

Secara sederhana terdapat tiga jenis alur cerita, yaitu:

\section{Alur Maju}

Pada alur maju peristiwa ditampilkan secara kronologis, maju, berurutan dari tahap awal, tahap tengah, sampai dengan tahap akhir cerita. Kelebihan dari alur ini mudah dipahami, namun biasanya digunakan oleh penulis pemula.

\section{Alur mundur}

Pada alur mundur, ceritanya dimulai dengan penyelesaian. Cerita yang setting waktunya pada masa lampau banyak memakai alur mundur.

\section{Alur campuran}

Alur campuran adalah suatu alur yang diawali dengan klimaks dari cerita, yang kemudian melihat lagi masa lalu atau masa lampau dan diakhiri dengan sebuah penyelesaian dari cerita tersebut (www.gurupendidikan.co.id, 2019).

\section{PEMBAHASAN}

Sasaran utama dari media ini adalah pria dan wanita yang tinggal di Kota Bandung dan berusia 26-40 tahun, kelas menengah ke atas, dan tertarik pada kebudayaan dan kesenian lokal dan gemar membaca buku. Target dipilih dari kalangan dewasa muda menengah ke atas karena harga buku yang relatif mahal dan hanya terjangkau oleh mereka yang sudah memiliki pekerjaan tetap dan berpenghasilan tinggi. 
Serat Rupa Journal of Design, January 2019, Vol.3, No.1: 25-33

E-ISSN: 2477-586X, ISSN: 2338-3348 | https://doi.org/10.28932/srjd.v3i1.811 | Received: 20-05-2018, Accepted: 25-01-2019 Sherilyn Silviani, Sandy Rismantojo, R.A. Dita Saraswati

Perancagan Buku Fotografi Dokumentasi Kegiatan Kesenian Di Kampung Jelekong

Mereka juga berdomisili di kota-kota besar di Jawa Barat terutama dari Kota Bandung agar terasa lebih dekat dengan subjek penelitian yang juga terletak di bagian selatan kota Bandung.

Sistem alur cerita dari buku ini menggunakan alur maju yang menceritakan suatu kejadian nyata secara berurutan dan dapat dari perspektif beberapa pihak agar pembaca dapat menyerap pesan dari buku ini dengan alur yang mengalir secara natural dari permulaan hingga akhir. Buku ini juga menggunakan fotografi sebagai media utamanya karena fotografi dapat menggambarkan sebuah kejadian dengan apa adanya dan merupakan bahasa visual yang universal dan dapat diterima oleh kalangan dewasa muda.

Jenis fotografi yang digunakan adalah fotografi dokumentasi dan human-interest karena gabungan kedua gaya ini dapat menunjukkan kegiatan kesenian rakyat Kampung Jelekong dan memperlihatkan sisi humanis dan perspektif mereka terhadap masalah yang dihadapi. Penulis memakai tone foto yang hangat untuk menggambarkan semangat rakyat Jelekong dalam melestarikan kesenian Sunda dan untuk memperkuat kesan kekeluargaan di antara mereka. Pendekatan visual isi buku menggunakan gaya clean design yang menggabungkan antara fotografi dengan typeface yang memiliki tingkat keterbacaan yang baik, sehingga lebih menonjolkan detail foto dan dapat menyampaikan informasi dengan efektif kepada target audience.

Tabel 1. Karya Perancangan

\begin{tabular}{|c|c|c|c|}
\hline No. & $\begin{array}{c}\text { Bagian } \\
\text { Buku }\end{array}$ & Gambar & Penjelasan \\
\hline 1. & $\begin{array}{l}\text { Dust } \\
\text { Jacket }\end{array}$ & & $\begin{array}{l}\text { Pada bagian dust jacket depan } \\
\text { dan belakang, foto yang dipilih } \\
\text { adalah tangan yang sedang } \\
\text { melukis di kanvas agar selaras } \\
\text { dengan judul buku yang } \\
\text { digunakan, yaitu "Goresan } \\
\text { Hidup Rakyat Jelekong". Judul } \\
\text { dan cover tersebut bermaksud } \\
\text { menggambarkan keberagaman } \\
\text { aktivitas kesenian yang } \\
\text { menjadi keunikan Kampung }\end{array}$ \\
\hline
\end{tabular}


Serat Rupa Journal of Design, January 2019, Vol.3, No.1: 25-33

E-ISSN: 2477-586X, ISSN: 2338-3348 | https://doi.org/10.28932/srjd.v3i1.811 | Received: 20-05-2018, Accepted: 25-01-2019 Sherilyn Silviani, Sandy Rismantojo, R.A. Dita Saraswati

Perancagan Buku Fotografi Dokumentasi Kegiatan Kesenian Di Kampung Jelekong

\begin{tabular}{|c|c|c|c|}
\hline & & & $\begin{array}{l}\text { Jelekong. Kata "goresan" pada } \\
\text { judul juga mengacu pada } \\
\text { pekerjaan utama mereka yaitu } \\
\text { membuat lukisan pesanan dan } \\
\text { untuk menggambarkan sisi } \\
\text { humanis kehidupan mereka. } \\
\text { Penulisan kata 'Jelekong' pada } \\
\text { judul buku ditulis secara } \\
\text { manual menggunakan kuas } \\
\text { dan cat akrilik hitam, yang } \\
\text { setelahnya diproses secara } \\
\text { digital dengan menggunakan } \\
\text { image trace. } \\
\text { Dipilih huruf yang dituliskan } \\
\text { secara manual agar } \\
\text { menunjukkan sifat kebebasan } \\
\text { kreatif dari efek kuas cat dan } \\
\text { penulisan huruf-huruf yang } \\
\text { tidak begitu seragam. }\end{array}$ \\
\hline 2. & $\begin{array}{l}\text { Sampul } \\
\text { Buku }\end{array}$ & 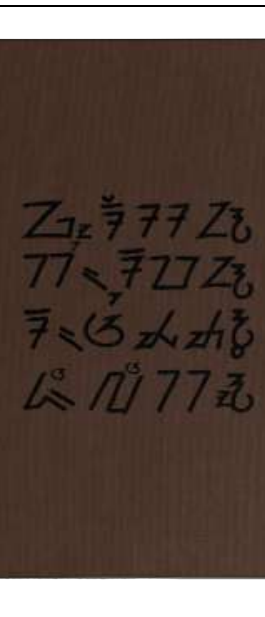 & $\begin{array}{l}\text { Bagian dust jacket menutupi } \\
\text { bagian sampul depan buku } \\
\text { yang menggunakan kertas } \\
\text { coklat tua bertekstur, Linmaster } \\
100 \text { gr. Permukaan sampul } \\
\text { depan buku bertuliskan judul } \\
\text { dari buku dalam bahasa dan } \\
\text { aksara Sunda yang ditulis } \\
\text { menggunakan efekbrush }\end{array}$ \\
\hline
\end{tabular}


Serat Rupa Journal of Design, January 2019, Vol.3, No.1: 25-33

E-ISSN: 2477-586X, ISSN: 2338-3348 | https://doi.org/10.28932/srjd.v3i1.811 | Received: 20-05-2018, Accepted: 25-01-2019 Sherilyn Silviani, Sandy Rismantojo, R.A. Dita Saraswati

Perancagan Buku Fotografi Dokumentasi Kegiatan Kesenian Di Kampung Jelekong

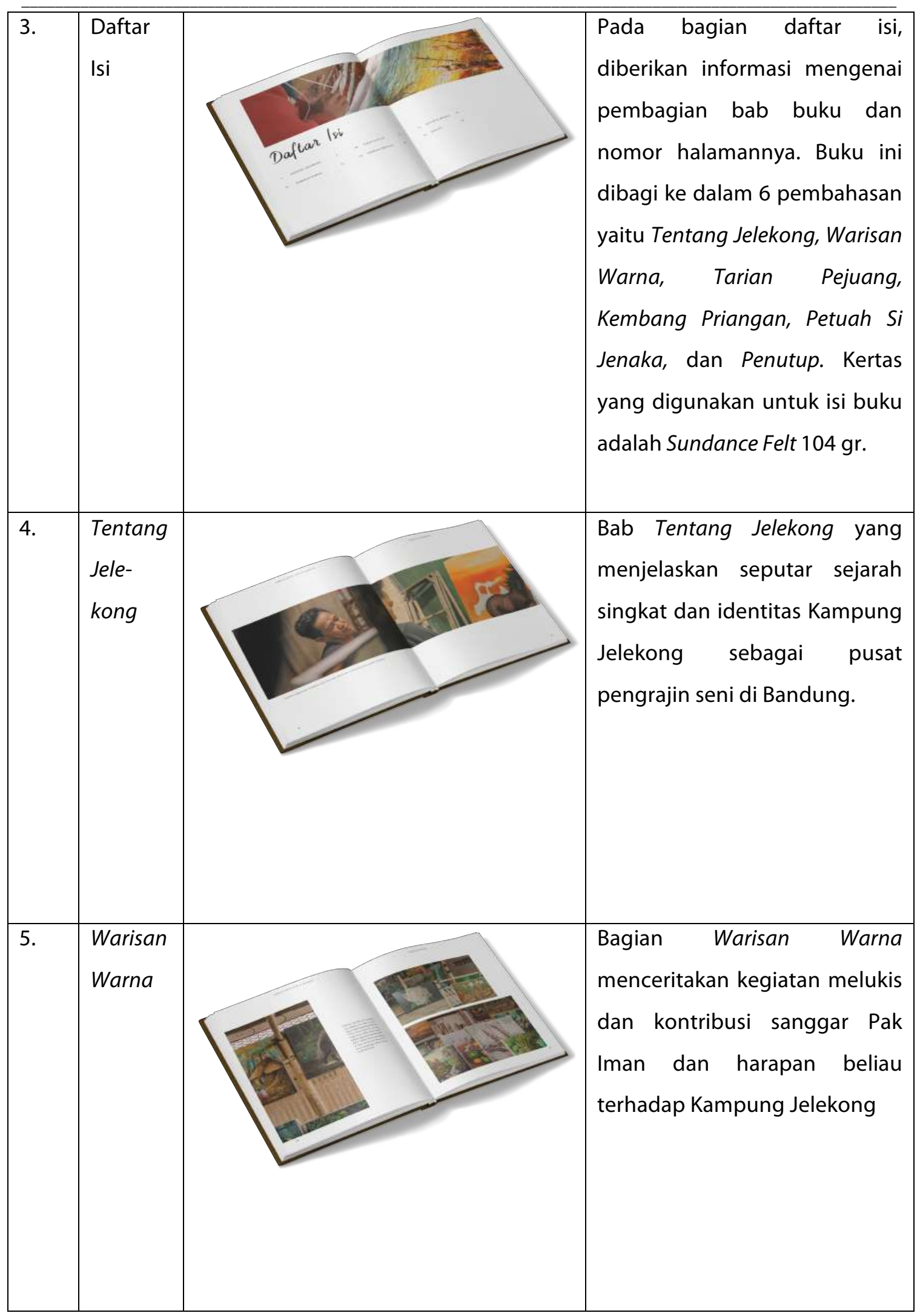


Serat Rupa Journal of Design, January 2019, Vol.3, No.1: 25-33

E-ISSN: 2477-586X, ISSN: 2338-3348 | https://doi.org/10.28932/srjd.v3i1.811 | Received: 20-05-2018, Accepted: 25-01-2019 Sherilyn Silviani, Sandy Rismantojo, R.A. Dita Saraswati

Perancagan Buku Fotografi Dokumentasi Kegiatan Kesenian Di Kampung Jelekong

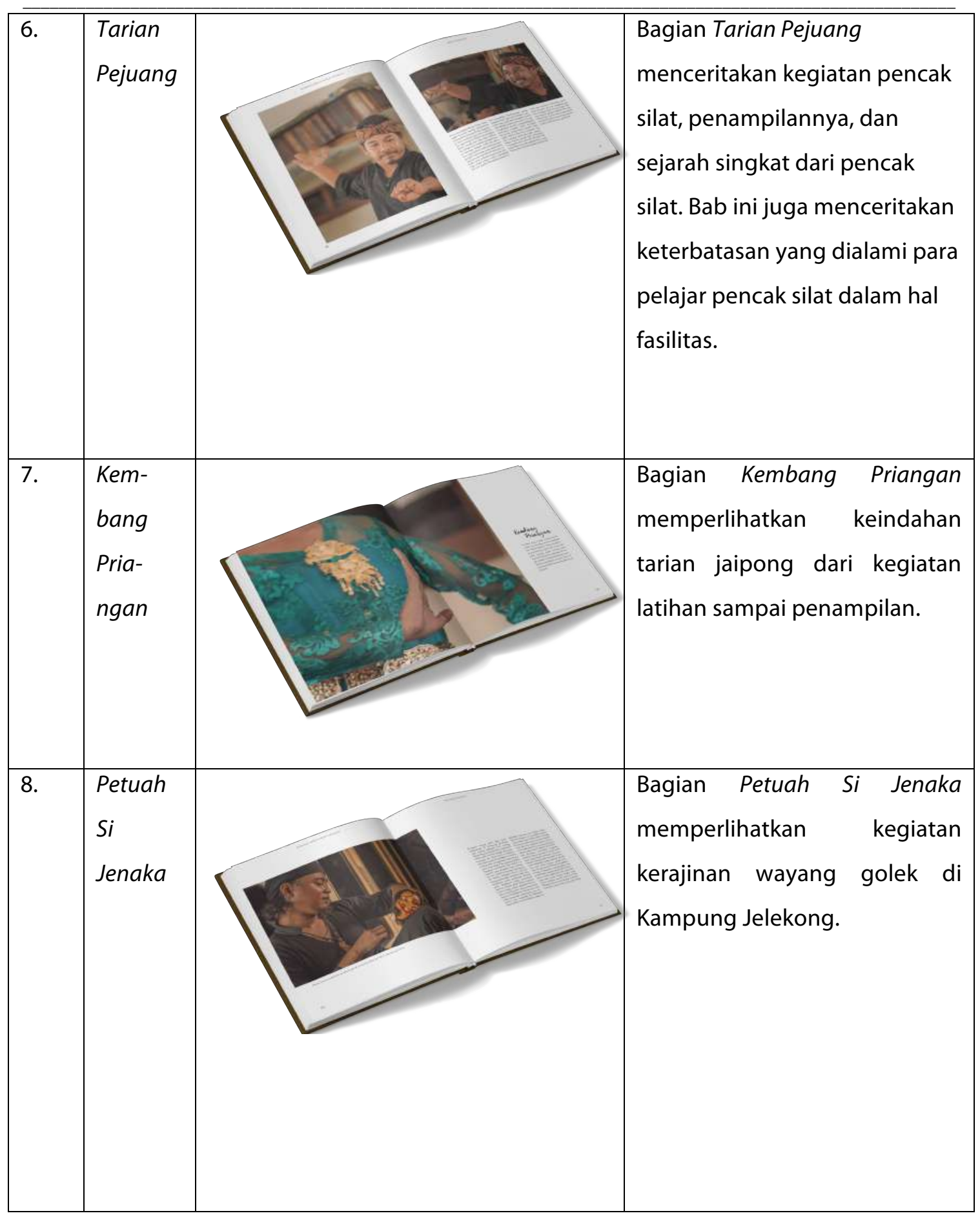


Serat Rupa Journal of Design, January 2019, Vol.3, No.1: 25-33

E-ISSN: 2477-586X, ISSN: 2338-3348 | https://doi.org/10.28932/srjd.v3i1.811 | Received: 20-05-2018, Accepted: 25-01-2019 Sherilyn Silviani, Sandy Rismantojo, R.A. Dita Saraswati

Perancagan Buku Fotografi Dokumentasi Kegiatan Kesenian Di Kampung Jelekong

\begin{tabular}{|l|l|l|l|}
\hline 9. & Penutup & $\begin{array}{l}\text { Bab terakhir dari buku ini } \\
\text { berisikan kesimpulan dan } \\
\text { penutup yang diharapkan } \\
\text { dapat menanamkan rasa } \\
\text { apresiasi terhadap kegiatan } \\
\text { kesenian di Kampung Jelekong }\end{array}$ \\
\hline
\end{tabular}

Sumber: Dokumentasi pribadi

\section{PENUTUP}

Buku ini dirancang untuk menampilkan kegiatan kesenian yang ada di Kampung Jelekong dan menceritakannya melalui fotografi dan teks tertulis yang dikemas secara objektif dan humanis. Media buku fotografi dokumentasi ini diharapkan dapat membuat masyarakat Bandung mengetahui dan menghargai semangat para pengrajin seni Kampung Jelekong dalam melestarikan kesenian Sunda dan dapat membantu rakyat Jelekong dalam mengembangkan usaha kesenian mereka.

\section{DAFTAR PUSTAKA}

Literatur Buku

Marien, Mary Warner. (2002). Photography: a Cultural History. London: Laurence King Publishing.

Grids. Amerika Serikat: Quatro Knows.

Samara, Timothy. (2002). Making and Breaking the Grid. Gloucester: Rockport Publishers.

Sudjojo, Marcus. (2010). Tak-Tik Fotografi. Jakarta: Bukuné.

Way, Wilsen. (2014). Human Interest Photography. Jakarta: PT Elex Media Komputindo.

Online

Bitar. (2019). Pengertian unsur dan jenis alur plot serta contohnya, diakses pada tanggal 15 januari 2019 dari https://www.gurupendidikan.co.id/pengertian-unsur-dan-jenis-alurplot-serta-contohnyal

Fotografiana. (2018). Pengertian Dokumenter, diakses pada tanggal 19 Januari 2018 dari http://fotografi.Upi.edu/home/6-keahlian-khusus/2-dokumenter\#TOC-PengertianFoto-Dokumenter. 